\title{
High northern latitude surface air temperature: comparison of existing data and creation of a new gridded data set 1900-2000
}

\author{
By SVETLANA I. KUZMINA ${ }^{1 *}$, OLA M. JOHANNESSEN ${ }^{2,3}$, LENNART BENGTSSON $^{4,5}$, \\ OLGA G. ANISKINA ${ }^{1}$ AND LEONID P. BOB YLEV ${ }^{1,2},{ }^{1}$ Nansen International Environmental and \\ Remote Sensing Center, St. Petersburg, Russia; ${ }^{2}$ Mohn-Sverdrup Center for Global Ocean Studies and Operational \\ Oceanography/Nansen Environmental and Remote Sensing Center, Bergen, Norway; ${ }^{3}$ Geophysical Institute, \\ University of Bergen, Norway; ${ }^{4}$ Max Planck Institute for Meteorology, Hamburg, Germany; ${ }^{5}$ Environmental Systems \\ Science Centre, University of Reading, UK
}

(Manuscript revised 23 March 2007; in final form 10 December 2007)

\begin{abstract}
Detection, attribution and understanding of temperature changes in the high northern latitudes depend on constraining uncertainties and resolving apparent discrepancies in observational data sets. We quantitatively compare four of the most widely used data sets of surface air temperature (SAT), and present a newly produced SAT data set, called NansenSAT. The existing data sets are highly correlated $(r \sim 0.8-0.9)$, except for some ocean areas. The evolution of SAT anomalies indicates differences reaching $3^{\circ} \mathrm{C}$ during the $1920 \mathrm{~s}-1930$ s warming period for the polar region $\left(60-90^{\circ} \mathrm{N}\right)$. Substantial errors in trends also result from spatial sampling limitations, especially during the early-20th-century. Maximum differences between the data sets reaching $0.64{ }^{\circ} \mathrm{C} / 100 \mathrm{yr}$ are found in 1900-1999 linear trends in July and October for $60-90^{\circ} \mathrm{N}$. We produced a new SAT data set for the region north of $40^{\circ} \mathrm{N}$ for the period $1900-2000$, using all available data and Objective Analysis methods. The new data set has been compared with existing SAT data. For the polar region, the magnitude of temperature-trend errors caused by sparse data coverage is about $0.5^{\circ} \mathrm{C} / 100 \mathrm{yr}$. The advantage of the new data set is its enhanced spatial coverage in high latitudes. The NansenSAT data set is available for the research community.
\end{abstract}

\section{Introduction}

Numerical-model simulations of climate change show the Arctic to be a region particularly sensitive to increased concentrations of greenhouse gases (GHGs), such that global warming is expected to be amplified in the high northern latitudes (Johannessen et al., 2004; Hansen et al., 2006; IPCC, 2007). There is already considerable observational evidence of recent changes in the high northern latitude climate system (Serreze et al., 2000; Polyakov et al., 2003; Johannessen et al., 2004; Overland et al., 2004; ACIA 2005; IPCC, 2007). However it is still under debate whether the warming observed in the Arctic in recent decades is predominantly an enhanced greenhouse-warming signal (Hansen et al., 1999, 2006; Jones et al, 1999) or natural multi-decadal variability (e.g. Schlesinger and Ramankutty, 1994; Polyakov and Johnson, 2000; Polyakov et al., 2002), although Johannessen et al. (2004)

\footnotetext{
*Corresponding author.

e-mail: svetlana.kuzmina@niersc.spb.ru

DOI: $10.1111 / \mathrm{j} .1600-0870.2008 .00303 . x$
}

found that 'there are strong indications that neither the warming trend nor the decrease of ice extent and volume over the last two decades can be explained by natural processes alone' and that the present warming is caused by GHGs, whereas the early warming was due to natural internal variability of the climate system (e.g. Bengtsson et al., 2004; Johannessen et al., 2004; Zhang et al., 2007).

Surface air temperature (SAT) is one of the major parameters or metrics used to map climate variability and change. Understanding the uncertainties and apparent discrepancies in temperature records is necessary for any definitive conclusion regarding the nature of temperature variability (Karl et al., 1993). The sources of errors and biases in temperature data, as reported by the Intergovernmental Panel on Climate Change (IPCC, 2007), include changes in observational times and instrumentation, station relocations, urban heat island bias, and inadequate spatial and temporal sampling. In the high northern latitudes and over the oceans, the sampling limitations are of primary importance.

The existing gridded temperature data sets are based on different compilations from meteorological stations and never use 
exactly the same data as input, although the vast majority of these data is in common (Jones et al., 1999). Several methods for interpolation of meteorological station data to a regular grid have been used, including the Climate Anomaly Method (CAM) (Jones et al., 1999), Reference Station Method (RSM) (Hansen and Lebedeff, 1987), First Difference Method (FDM) (Peterson et al., 1998) and Objective Analysis (OA), which includes Optimal Interpolation (OI) techniques (Gandin, 1965; Vinnikov, 1977). Peterson et al. (1998) considered three different gridding techniques (CAM, FDM and RSM) and evaluated the magnitude of the errors associated with the existing methods of calculating global SAT changes. It was shown that the differences in global trends obtained by these three methods were as small as a few hundredths of a degree per $100 \mathrm{yr}$. However, this is not the case for regional trends. In the high northern latitudes, different spatial-temporal coverage led to some discrepancies in the temperature variability and trends during the last century (e.g. Jones et al., 1999; Przybylak, 2000; Polyakov et al., 2002). Therefore, there is a strong need to perform a comparison of the existing high-latitude temperature data sets in order to estimate the differences between them and the potential implications for assessing climate variability and change. To address this issue, we compare four gridded data sets of SAT widely used in climate studies: Jones et al. (1999), Jones and Moberg (2003) (J); Hansen et al. (1999) (H); Alekseev and Svyaschennikov (1991), Alekseev et al. (1999) (A); ERA-40 Reanalysis data from ECMWF (E) (Uppala et al., 2005), hereafter referred to as $\mathbf{J}, \mathbf{H}, \mathbf{A}$ and $\mathbf{E}$, respectively. We conducted a spatio-temporal comparision for the region north of $40^{\circ} \mathrm{N}$ to identify correlations and differences in anomalies and trends over different time periods and seasons.

The analysis shows that these SAT data sets have major gaps in the high northern latitudes, in particular over the Arctic Ocean and some surrounding land areas. In particular, it was shown that large differences, reaching $3{ }^{\circ} \mathrm{C}$, in averaged monthly temperature anomalies between the data sets occurred during the early-20th-century warming period of 1920-1940 for the area $60-90^{\circ}$ N. Differences in the order of tenths of degrees in 1900 1999 linear trends were also found, especially for the polar region $\left(60-90^{\circ} \mathrm{N}\right)$. In autumn (October), the maximum difference between trends was as high as $0.64{ }^{\circ} \mathrm{C} / 100 \mathrm{yr}$.

However, there are several methods that can improve the spatial resolution of the gridded data, even when station information is scarce. OA including OI provides a suitable method for spa- tial averaging, especially when handling sparse data from a limited number of stations (Gandin, 1965; Vinnikov, 1977; Kagan, 1997).

Therefore we have produced a new gridded data set of SAT for high northern latitudes, which has the advantage of using all available data based on the OA technique. The new analysis has been performed with a resolution of $2.5^{\circ} \times 2.5^{\circ}$ for the period 1900-2000. Estimates of the typical SAT distributions and trends for different time periods were obtained as well as estimations of the interpolation errors. The advantage of the new data set is that all available data is included enhancing spatial coverage in high northern latitudes, due to the ability of OA to optimise the data where information is scarce.

The paper is organised as follows. Section 2 provides a description of existing SAT data sets. Section 3 provides a comparison of SAT fields from these data sets. Data for producing a new data set and procedure applied are described in Section 4, with the computational details of this procedure given in the Appendix A. An analysis of the new SAT data set is presented in Section 5. Summary and conclusions are given in Section 6.

\section{Existing SAT data sets}

The four different data sets analysed are summarised in Table 1 and their characteristics are described below.

\subsection{Data set $A$}

Arctic and Antarctic Research Institute (AARI) data set focused on the high northern latitudes (Alekseev and Svyaschennikov 1991; Alekseev et al., 1999; Johannessen et al., 2004). Data set A is a century-long gridded data set based on daily temperatures from some 1500 meteorological stations including land and drifting stations in the Arctic. This data set was developed from several sources: (1) monthly mean SAT anomaly maps produced by the USSR's Voeikov Main Geophysical Observatory for the period 1891-1969 and the Hydrometeorological Research Center for the period 1970-1976; (2) maps interpolated into a gridded data set using OI technique (Gandin, 1965; Vinnikov, 1977); (3) DATA set extension for the period 1977-1986 (Alekseev and Svyaschennikov, 1991); (4) data set extension by the Hydrometeorological Research Center from 1986 to 1995 and (5) monthly mean SATs produced at AARI since 1995 using daily temperatures from ECMWF.

Table 1. Summary specifications of the gridded surface air temperature data sets

\begin{tabular}{lcccc}
\hline Data set & Period & Resolution & Gridding method & References \\
\hline E & $1957-2002$ & $2.5^{\circ} \times 2.5^{\circ}$ & Reanalysis, ECMWF & Uppala and co-authors (2005) \\
A & $1891-1999$ & $5^{\circ} \times 10^{\circ}$ & Objective and Synoptic analysis & Alekseev and Svyaschennikov (1991), Alekseev et al. (1999) \\
J & $1870-2002$ & $5^{\circ} \times 5^{\circ}$ & Climate Anomaly Method (CAM) & Jones et al. (1999), Jones and Moberg (2003) \\
H & $1880-1999$ & $1^{\circ} \times 1^{\circ}$ & Reference Station Method (RSM) & Hansen et al. (1999) \\
\hline
\end{tabular}




\subsection{Data set $J$}

Jones et al. (1999) and Jones and Moberg (2003) global gridded SAT data set. Data set $\mathbf{J}$ is essentially akin to the CRUTEM2v data set (see Section 4.1), is based on global monthly temperature time series from $\sim 3000$ meteorological stations and sea-surface temperature (SST) measurements taken from vessels. Land and marine components are separately interpolated to the same grid. For the interpolation, the CAM was used. This technique requires that data from each station are reduced to anomalies from monthly means calculated for a common period (1961-1990). Grid-box SAT anomalies are produced by averaging of the station anomaly values within each grid box.

\subsection{Data set $H$}

Hansen et al. (1999) data set from the Goddard Institute for Space Sciences (GISS) is based on data from about 2000 global meteorological stations around the world. The interpolation is done using the Reference Station Method, as follows. The Earth's surface is divided into a number of equal area 'boxes'. The single reference station having the longest record is selected within each box. The other stations are ordered by decreasing record length. Data from each shorter record station are then successively adjusted in such a way that their average should be equal to the composite of all the stations that were previously processed. Then distance-weighted grid cell averages are calculated. The SST data are derived from a combined analysis of satellite and in situ ship measurements by Reynolds and Smith (1994) for the period since 1982. The SST data for 1950-1981 are based only on in situ data (Smith et al., 1996).

\subsection{Data set $E$}

European Centre for Medium-Range Weather Forecasts (ECMWF) Re-Analysis (ERA-40) (Uppala et al., 2005). Data set E, the ERA-40 data set, is based on the observations worldwide involving comprehensive use of satellite data and also revitalizing data from past field experiments. The number of global surface observations per day varies from $\sim 10000$ to $\sim 40000$. SST anomalies are derived from the analyses of Rayner et al. (2003), which were used in ERA-40 until 1981; thereafter, similar analyses from the National Center for Environmental Prediction (NCEP, Reynolds et al., 2002) were used. The surface analysis and grid interpolation are produced using OI techniques (Douville et al., 1998).

\section{Comparison of SAT fields from existing data sets}

For our analysis, we have extracted from the four gridded data sets temperature data for the region $40-90^{\circ} \mathrm{N}$ during the time period 1900-1999, apart from ERA-40 data which started in
1957. The base reference period of 1961-1990 was chosen because it has the best data coverage. For direct comparison, we used temperature anomalies relative to this reference period. The temperature data of the data sets considered here are provided on different grids with different resolution. Therefore, to facilitate direct inter-comparison, all the data were re-interpolated to a common $2.5^{\circ} \times 2.5^{\circ}$ regular grid.

\subsection{Spatially averaged time series}

We selected temperature anomalies for four mid-season months, that is, January, April, July and October, in two latitudinal zones: $40-60^{\circ} \mathrm{N}$ and $60-90^{\circ} \mathrm{N}$. For spatial averaging, the cosine of the central latitude of each grid box was applied as a weighting factor. It was found that the differences between non-smoothed $\mathbf{A}, \mathbf{J}$ and $\mathbf{H}$ time series were large in the first half of the 20th century for monthly averaged for the region $\left(60-90^{\circ} \mathrm{N}\right)$. In January, the differences are the largest during 1940s and reach $\sim 3{ }^{\circ} \mathbf{C}$ for $\mathbf{A}$ and $\mathbf{J}, \sim 2.5^{\circ} \mathbf{C}$ for $\mathbf{A}$ and $\mathbf{H}$ and $\sim 1.0{ }^{\circ} \mathbf{C}$ for $\mathbf{H}$ and $\mathbf{J}$ data sets. In October, the largest differences were found in the beginning of the century (1911-1919): $\sim 2{ }^{\circ} \mathbf{C}$ for $\mathbf{A}$ and $\mathbf{H}, \sim 2{ }^{\circ} \mathbf{C}$ for $\mathbf{A}$ and $\mathbf{J}$ and $\sim 1.6{ }^{\circ} \mathbf{C}$ for $\mathbf{H}$ and $\mathbf{J}$. A closer agreement between these time series is observed for the region $40-60^{\circ} \mathrm{N}$ in July and April.

The expected differences between data sets also exist for smoothed time series. Figure 1 shows 11-yr running means of the monthly SAT anomalies. It is seen that all the four temperature data sets exhibit two distinct periods of warming: 1920-1940, especially in the polar region $\left(60-90^{\circ} \mathrm{N}\right)$, and since the mid-1970s and onwards.

The linear trends of 1900-1999 temperature time series are presented in Table 2a. Large differences were found between the $\mathbf{A}$ and other data sets (for $\mathbf{A}$ and $\mathbf{J} \sim 0.64^{\circ} / 100 \mathrm{yr}$ in July, $\sim 0.6^{\circ} / 100 \mathrm{yr}$ in October; for $\mathbf{A}$ and $\mathbf{H} \sim 0.45^{\circ} / 100 \mathrm{yr}$ in October). We explain this by a better spatial coverage in high latitudes for data set $\mathbf{A}$ where data from north-pole drifting stations are also included. A difference was also found between the $\mathbf{H}$ and $\mathbf{J}$ trends, with the largest value, $\sim 0.46^{\circ} / 100 \mathrm{yr}$, observed in July.

Comparison of the $\mathbf{E}$ data with data sets $\mathbf{A}, \mathbf{J}$ and $\mathbf{H}$ for the common ERA-40 period since 1958 shows reasonably good agreement. Linear trends for the period 1958-1999 are presented in the Table $2 b$. Trends are systematically lowest in the $\mathbf{E}$ data. This is in agreement with Simmons et al. (2004), who demonstrated that for the period 1958-2001 the ERA-40 trend in 2-m temperature for the Northern Hemisphere is $\sim 30 \%$ smaller than the $\mathbf{J}$ trend.

\subsection{Zonal averages}

We considered the time evolution of the zonally averaged SAT anomalies for the period $1900-1999$ for $40-90^{\circ} \mathrm{N}$ in January, July, April and October. Two warming events stand out, the first from the 1920 s to about 1940 and the second starting in 

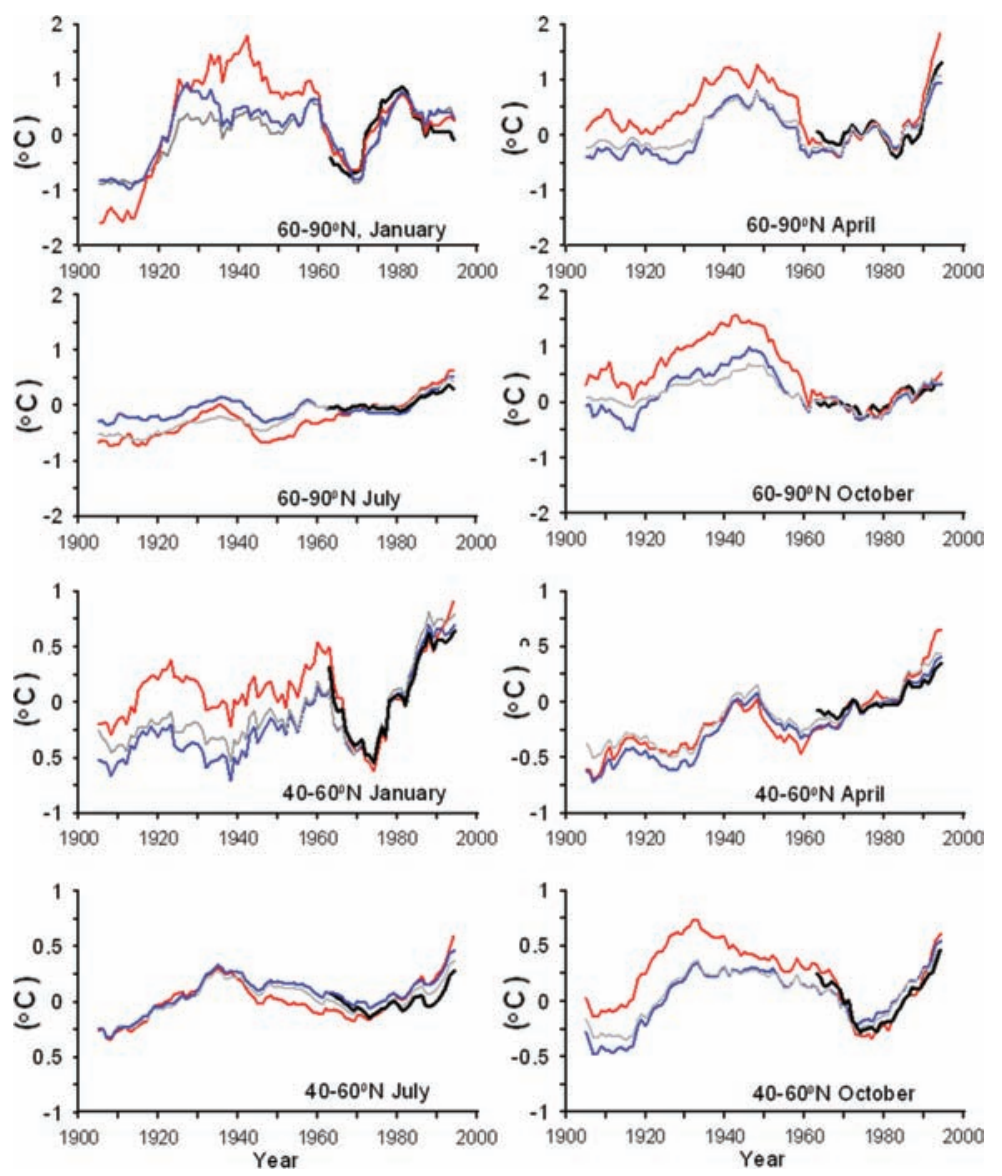

Fig. 1. 11-yr running means of the SAT anomalies from $\mathbf{A}$ (red), J (blue), $\mathbf{H}$ (grey) and $\mathbf{E}$ (black) data sets in January, July, April and October for different latitudinal zones: $60-90^{\circ} \mathrm{N}$ and $40-60^{\circ} \mathrm{N}$.

Table 2. Temperature trends for months representing different seasons over the periods 1900-1999 (a) and 1958-1999 (b) calculated using linear least squares. Significance at the 95\% confidence level is highlighted in bold

\begin{tabular}{|c|c|c|c|c|c|c|c|c|}
\hline \multirow[t]{2}{*}{ Data set } & \multicolumn{2}{|c|}{$60-90^{\circ} \mathrm{N}$} & \multicolumn{2}{|c|}{$40-60^{\circ} \mathrm{N}$} & \multicolumn{2}{|c|}{$60-90^{\circ} \mathrm{N}$} & \multicolumn{2}{|c|}{$40-60^{\circ} \mathrm{N}$} \\
\hline & January & July & January & July & April & October & April & October \\
\hline \multicolumn{9}{|c|}{ (a) $1900-1999$ trends $\left({ }^{\circ} \mathrm{C} / 100 \mathrm{yr}\right)$} \\
\hline A & 1.36 & 1.20 & 0.52 & 0.54 & 0.54 & -0.42 & 1.04 & 0.01 \\
\hline $\mathbf{J}$ & 0.93 & 0.56 & 1.02 & 0.49 & 0.89 & 0.18 & 0.98 & 0.57 \\
\hline $\mathbf{H}$ & 1.12 & 1.02 & 0.84 & 0.39 & 0.68 & $\mathbf{0 . 0 3}$ & 0.79 & 0.37 \\
\hline \multicolumn{9}{|c|}{ (b) 1958-1999 trends $\left({ }^{\circ} \mathrm{C} /\right.$ decade $)$} \\
\hline A & 0.14 & 0.28 & 0.19 & 0.22 & 0.57 & 0.16 & 0.28 & 0.11 \\
\hline $\mathbf{J}$ & 0.15 & 0.17 & 0.23 & 0.13 & 0.35 & 0.12 & 0.20 & 0.14 \\
\hline $\mathbf{H}$ & 0.19 & 0.15 & 0.25 & 0.12 & 0.36 & 0.13 & 0.20 & 0.12 \\
\hline $\mathbf{E}$ & 0.12 & 0.10 & 0.15 & 0.07 & 0.34 & 0.12 & 0.14 & 0.07 \\
\hline
\end{tabular}

mid-1970s and still ongoing. The early-20th-century warming was largely confined to the north of $60^{\circ} \mathrm{N}$ whereas the latter warming is spread over lower latitudes (Jones et al., 1999; Johannessen et al., 2004), both enhanced in the Arctic. The early20th-century warming trend in the Arctic was nearly as large as the warming trend for the last $20 \mathrm{yr}$, and has been considered by some researchers (e.g. Polyakov et al., 2002) as a part of a natural low-frequency oscillation.

The analysis indicates discrepancies of up to $1.5^{\circ} \mathrm{C}$ between the data sets for the 1920s-1940s for the 11-yr running means. In January, April and especially in October, warming was confined to the high latitudes in the $\mathbf{A}$ and $\mathbf{J}$ data, whereas warming 
Table 3. Temperature trends $\left({ }^{\circ} \mathrm{C} / 100\right.$ years) for the new data set (NansenSAT) and CRUTEM2v. Trends significant at $\alpha<0.05$ are highlighted in bold

\begin{tabular}{lcclcc}
\hline \multirow{2}{*}{ Month } & \multicolumn{2}{c}{ NansenSAT } & & \multicolumn{2}{c}{ CRUTEM2v } \\
\cline { 2 - 3 } \cline { 5 - 6 } & $60-90^{\circ} \mathrm{N}$ & $40-60^{\circ} \mathrm{N}$ & & $60-90^{\circ} \mathrm{N}$ & $40-60^{\circ} \mathrm{N}$ \\
\hline January & $\mathbf{1 . 0 5}$ & $\mathbf{0 . 9 6}$ & & $\mathbf{0 . 9 3}$ & $\mathbf{1 . 0 2}$ \\
July & 0.11 & 0.12 & & $\mathbf{0 . 5 6}$ & $\mathbf{0 . 4 9}$ \\
April & 0.15 & $\mathbf{0 . 6 9}$ & & $\mathbf{0 . 8 9}$ & $\mathbf{0 . 9 8}$ \\
October & 0.30 & 0.31 & & 0.18 & $\mathbf{0 . 7 0}$ \\
\hline
\end{tabular}

is less apparent in the $\mathbf{H}$ data. In July, warming is only found in $\mathbf{J}$ data set, while $\mathbf{A}$ and $\mathbf{H}$ indicate lower temperatures. Distributions of zonally averaged temperature anomalies north of $40^{\circ} \mathrm{N}$ for later period, 1958-1999, in January, July, April and October are in a good agreement for all data sets. The second warming period started in the mid of 1970s in high northern latitudes and then encompassed the lower latitudes. This is evident from all data sets. Some discrepancies can be found only for the period before 1970s, when compared with other data sets, $\mathbf{E}$ is cooler in January and is warmer in April. This is explained by the gaps in data coverage for ERA-40 before 1967 (Simmons et al., 2004).

\subsection{Spatial distribution of temperature trends}

As a next step, we considered spatial distribution of SAT linear trends and regional differences between them. Figure 2 shows observed temperature trends from data sets $\mathbf{J}, \mathbf{A}$ and $\mathbf{H}$ north of $40^{\circ} \mathrm{N}$ in January for 20 -yr periods representing major warming (1920-1939) and cooling (1945-1964) periods in the 20th century. Figure 3 indicates observed temperature trends in July for the same periods. For the warming period 1920-1939, common features for all the data sets are cooling over the Central Asia and Siberia and the strongest warming over the eastern part of the North America in January. In July, warm anomalies occupied the whole North America and European part of Russia, while cooling occurred over Central Asia.

Differences between the data sets become apparent for the ocean areas. In January, the $\mathbf{J}$ and $\mathbf{H}$ data demonstrate significant warming over the North Atlantic and some Pacific areas, while the A data show merely an insignificant cooling. In July, the $\mathbf{J}$ data demonstrate significant cooling for some Pacific areas whereas the A data shows positive trends. For the ocean, such differences are quite essential because even the small trends over some oceanic areas are significant because of a low variability in year-to-year temperature values. In contrast to others, data set $\mathbf{A}$ also shows warming over Greenland and Scandinavia in January and July and over the Barents Sea in July. a) $1920-39$

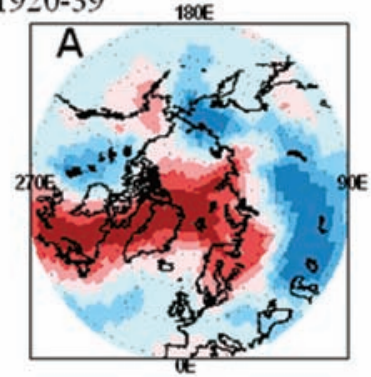

b) $1945-64 \quad$ 180E

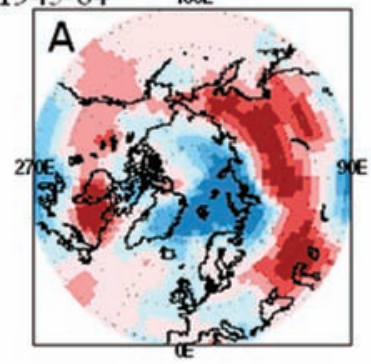

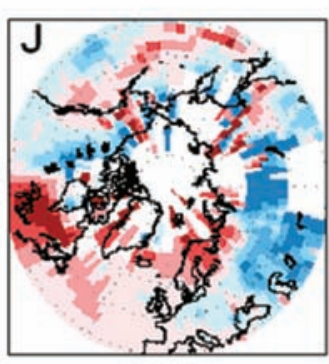
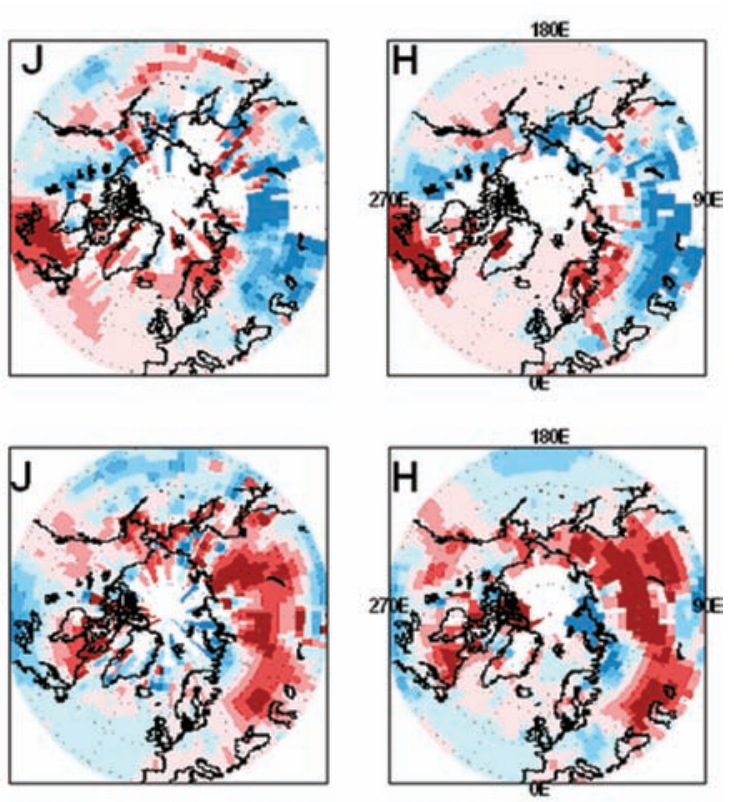

( $\left.{ }^{\circ} \mathrm{C} / 20 \mathrm{yr}\right)$

Fig. 2. Observed SAT trends from $\mathbf{A}, \mathbf{J}$ and $\mathbf{H}$ data sets north of $40^{\circ} \mathrm{N}$ in January for 20 -yr periods representing warming (a) and cooling (b) in the 20th century. 
a) $1920-39$
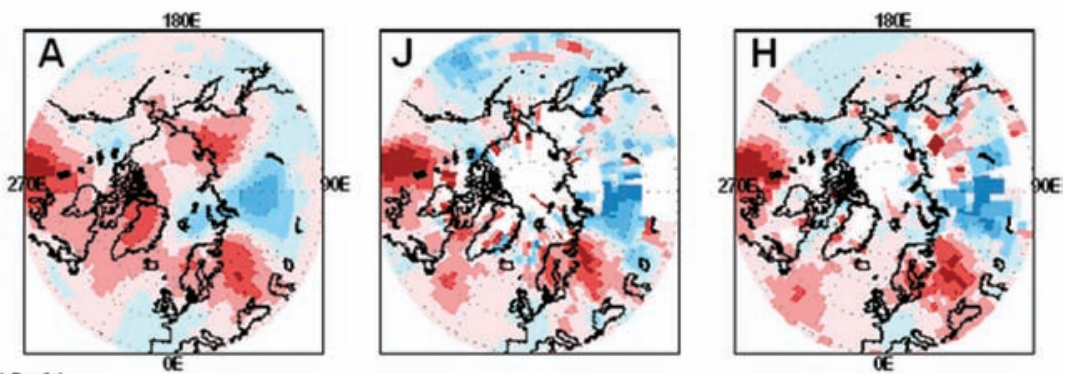

b) $1945-64$
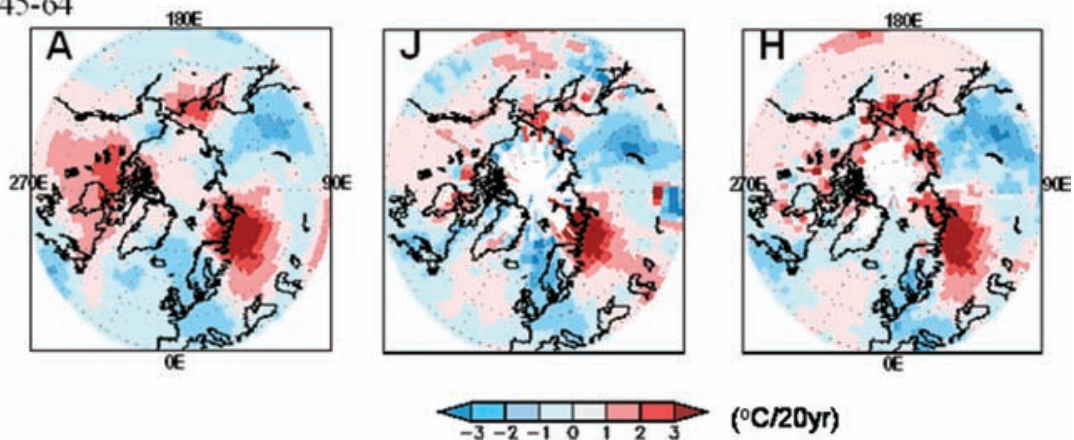

Fig. 3. Observed SAT trends from $\mathbf{A}, \mathbf{J}$ and $\mathbf{H}$ data sets north of $40^{\circ} \mathrm{N}$ in July for 20 -yr periods representing warming (a) and cooling (b) in the 20th century.

Cooling patterns for 1945-1964 are very similar for all the data sets both in January and July, although significant cooling in Russian Arctic in January is apparent only in data set A. In addition, small trends over ocean areas are of opposite sign for the $\mathbf{A}$ data vis-à-vis data sets $\mathbf{J}$ and $\mathbf{H}$ in particular in the Pacific Ocean.

Figure 4 illustrates the observed temperature trends north of $40^{\circ} \mathrm{N}$ in January and July for 1980-1999. Here we compared

a) January
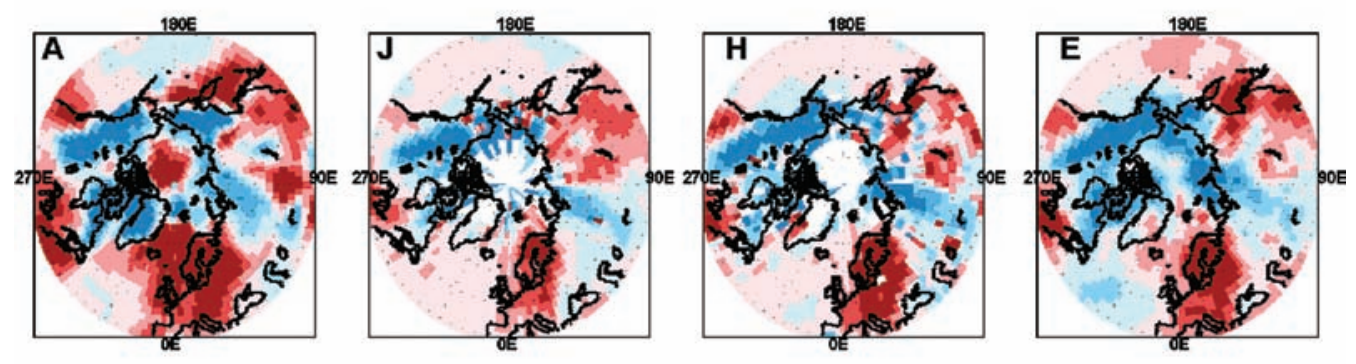

b) July
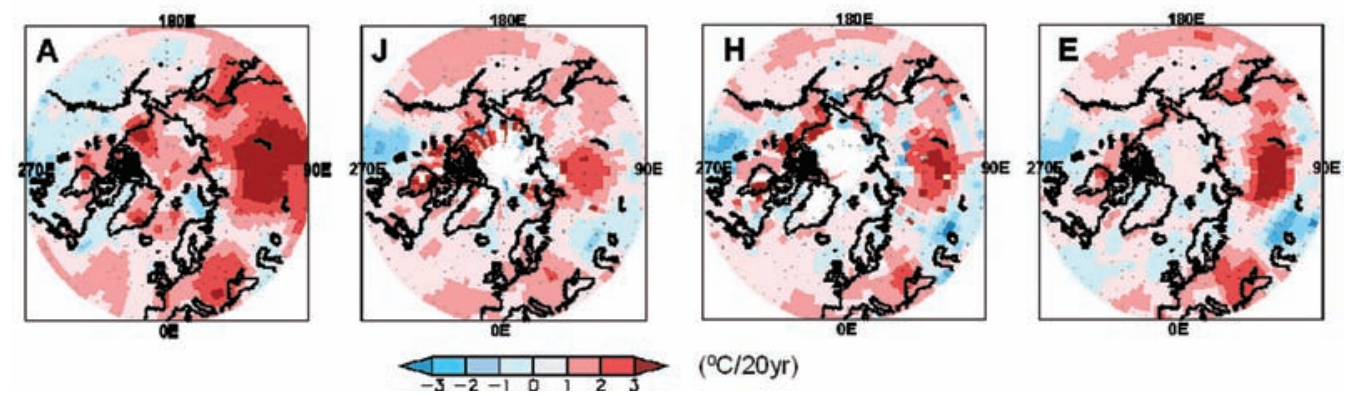

Fig. 4. Observed temperature trends north of $40^{\circ} \mathrm{N}$ in January (a) and July (b) for 1980-1999. 

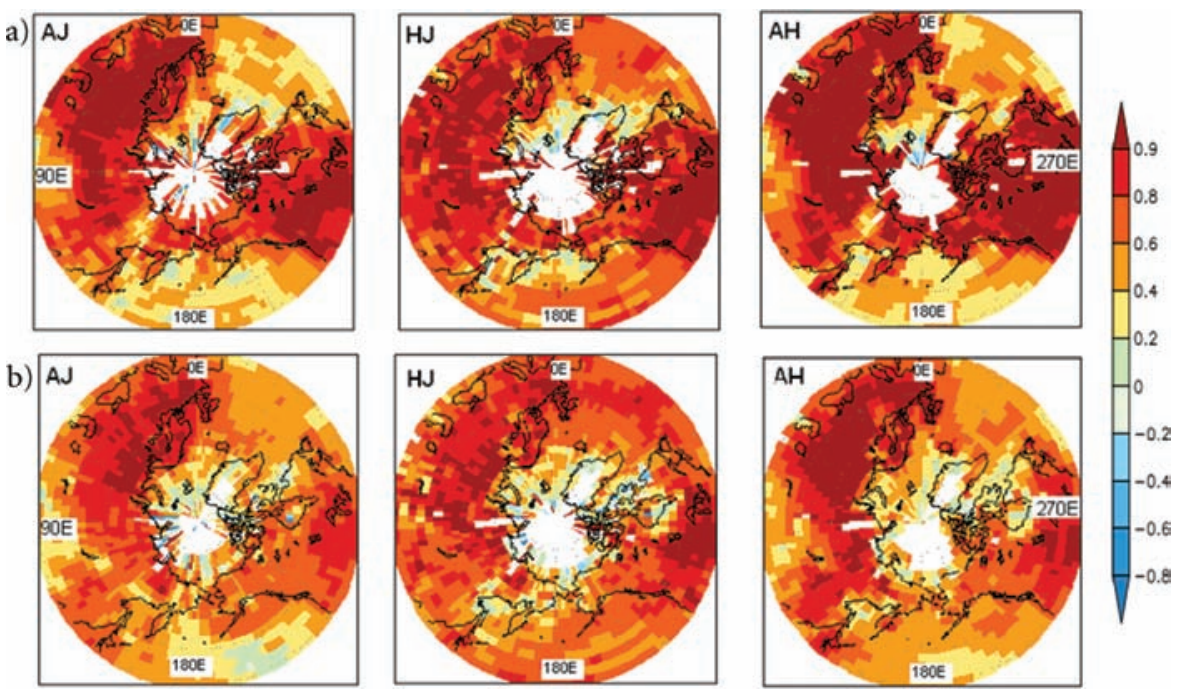

Fig. 5. Correlation of temperature anomalies between A, J and H data sets for 1900-1999 in January (a) and July (b).

data sets $\mathbf{J}, \mathbf{A}$ and $\mathbf{H}$ including ERA-40 reanalysis data. Both the 1920-1939 and 1980-1999 warming (Figs. 2a, 3a and 4a) are most pronounced in January. However the warming trend for 1980-1999 is more widespread and its pattern is different compared to the earlier periods in both winter and summer. The pattern of recent warming is strongest over Scandinavia in January and northern Eurasia, especially eastern Siberia. There is also a pronounced warming in the Eurasian mid-latitudes, especially in summer. This pattern is common for all the data sets. The major difference between the trends for $\mathbf{A}$ and $\mathbf{E}$ is warming in the central Arctic from the $\mathbf{A}$ data in January, with the $\mathbf{E}$ data showing slight cooling.

\subsection{Correlation between data sets}

We calculated the correlation of temperature anomalies between data sets A, J and $\mathbf{H}$ for a hundred-year period 1900-1999 for January and July (Fig. 5). A statistically significant correlation was found between all the data sets for both seasons except for some ocean areas at high latitudes. The highest correlation (correlation coefficient $r \sim 0.8-0.9$ ) was found for land areas, especially over North America and western Europe, where the station density was higher While the correlation between the data sets $\mathbf{A}-\mathbf{J}$ and $\mathbf{A}-\mathbf{H}$ for the oceanic areas is lower $(r \sim 0.2-0.4)$.

Additionally, the temperature anomalies found for data sets $\mathbf{A}$, J, $\mathbf{H}$ were correlated with $\mathbf{E}$ data set for the ERA-40 reanalysis period 1958-1994. This period was chosen in order to avoid computing correlations for overlapping data sets because starting from 1995 daily SAT values from ECMWF were also including in the A data set. A significant correlation $(r \sim 0.8-0.9)$ was found between all the data sets for both seasons, except some ocean areas at high latitudes and Greenland. A weak correlation between the $\mathbf{E}-\mathbf{J}$ and $\mathbf{E}-\mathbf{A}$ data was also found for some Pacific areas in January and July, respectively.
The low correlations found between the temperature data over the ocean regions are partly due to the small temperature variability over oceans. Moreover, different sources of temperature data were used. For the $\mathbf{E}, \mathbf{J}$ and $\mathbf{H}$ data sets, SST data were used whereas for data set $\mathbf{A}$, temperatures over the ocean areas were derived by a combined use of optimal and visual interpolation of data from meteorological stations and some weather ships.

Because of the above-described discrepancies between the four gridded data sets, we were motivated to create a new gridded data set using all available observations for 1900-2000 from $40^{\circ} \mathrm{N}$ to the North Pole, interpolated to a $2.5^{\circ} \times 2.5^{\circ}$ grid using the OA technique.

\section{Creation of a new SAT data set}

\subsection{Data}

The main source of data used to create the new data set was monthly mean SAT meteorological station data, based primarily on the Climatic Research Unit (CRU) data set (http://www.cru. uea.ac.uk). The quality of the CRU data set is considered high due to extensive homogeneity assessments performed by Jones and others (e.g. Jones and Moberg, 2003). Figure 6 shows the number of stations used each year for the area north of $40^{\circ} \mathrm{N}$ in the CRU data set. The number of stations is limited during the beginning of the century and reaches its maximum during the period 1950-1990. During recent years, one can note the considerable reduction in the number of stations, as has been discussed by Jones and Moberg (2003).

In addition, for the second half of the 20th century, we included SAT observations obtained from buoys, manned drifting stations and meteorological land stations in the Arctic during 1979-1997 (Rigor et al., 2000) as well as SAT data from Russian 'North Pole' drifting stations for years from 1937 to 1991 , 


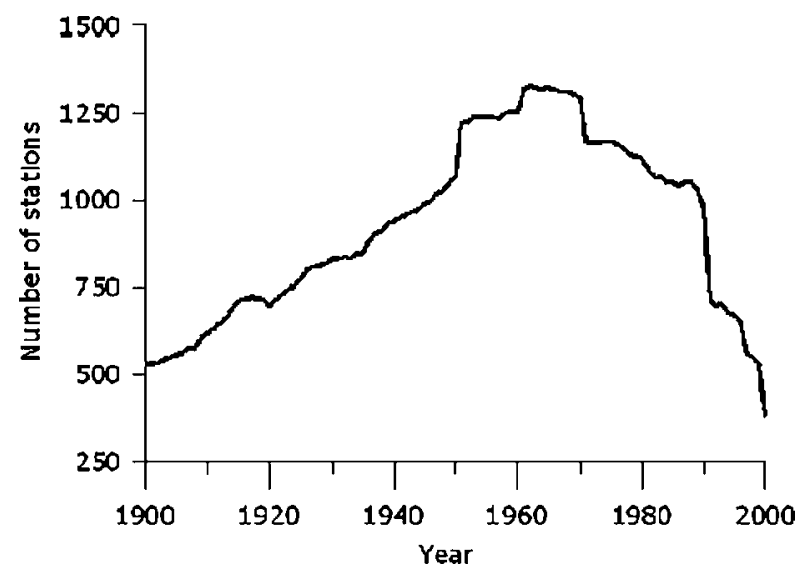

Fig. 6. Number of meteorological stations used in Climate Research Unit (CRU) data set for the region to the north of $40^{\circ} \mathrm{N}$ by year.

as published in 'Arctic Meteorology and Climate Atlas' developed by the Arctic and Antarctic Research Institute, St. Petersburg, Russia, the University of Washington, Seattle, USA and the National Snow and Ice Data Center, University of Colorado, Boulder, USA (Arctic Climatology Project, 2000; Alexandrov et al., 2004; Frolov et al., 2005). The data in the section 'Floating Platform Data' from this atlas provide observations with better spatial and temporal coverage for the Arctic Ocean than has generally been available in the past. Figure 7 shows the spatio-temporal distribution of the data from drifting stations and buoys in January; the distribution for the other months is similar. Figure 7 a shows the location of the Russian drifting stations and the number of stations in different years. The average position of all drifting stations is $82^{\circ} \mathrm{N}, 175^{\circ} \mathrm{W}$. Figure $7 \mathrm{~b}$ shows the same for ARGOS buoys.

\subsection{Methodology}

We produced the new gridded SAT data set using the OA method with OI techniques, generally following Douville et al. (1998). Details of the method adjusted for our task are given in the Appendix A. The analysis was performed for all points of a regular grid with a resolution of $2.5^{\circ} \times 2.5^{\circ}(144 \times 21$ grid points $)$ for the period 1900-2000. Calculation of the background climatology or the SAT monthly climatic 'norms' and autocorrelation functions was performed using $2 \mathrm{~m}$ air temperature from the ERA-40 data for the period 1961-1990. Autocorrelation coefficients are calculated as follows: (1) data pairs of temperature are formed by subtracting the temporal average from the temperature at each grid point; (2) the set of data pairs is then used to compute the correlation coefficients between different grid points; (3) calculation of the fitting is made by means of a nonlinear procedure using an exponential model $c=a+\exp \left(b_{0}+b_{1} \times R\right)$, where $R$ is a distance between observational points in hundreds of kilometres. For instance, coefficients $a, b_{0}$ and $b_{1}$ were found to be: $-0.57,+0.47$ and -0.04 , respectively, for January, and -0.34 , +0.32 and -0.07 for July.

Because the station density varies considerably, we introduced 'super-obbing', which here is the statistical average of observations from all stations within an area with a radius of some $100 \mathrm{~km}$. This means that one idealised station represents all stations within this particular area. The accuracy of the 'super-obs' obviously increases if more stations are averaged.

\section{New SAT data set performance}

In order to perform quality control and testing of our new gridded data set (hereinafter 'NansenSAT' or data set $\mathbf{N}$ ), we compared it with the CRUTEM2v data set, which was created using
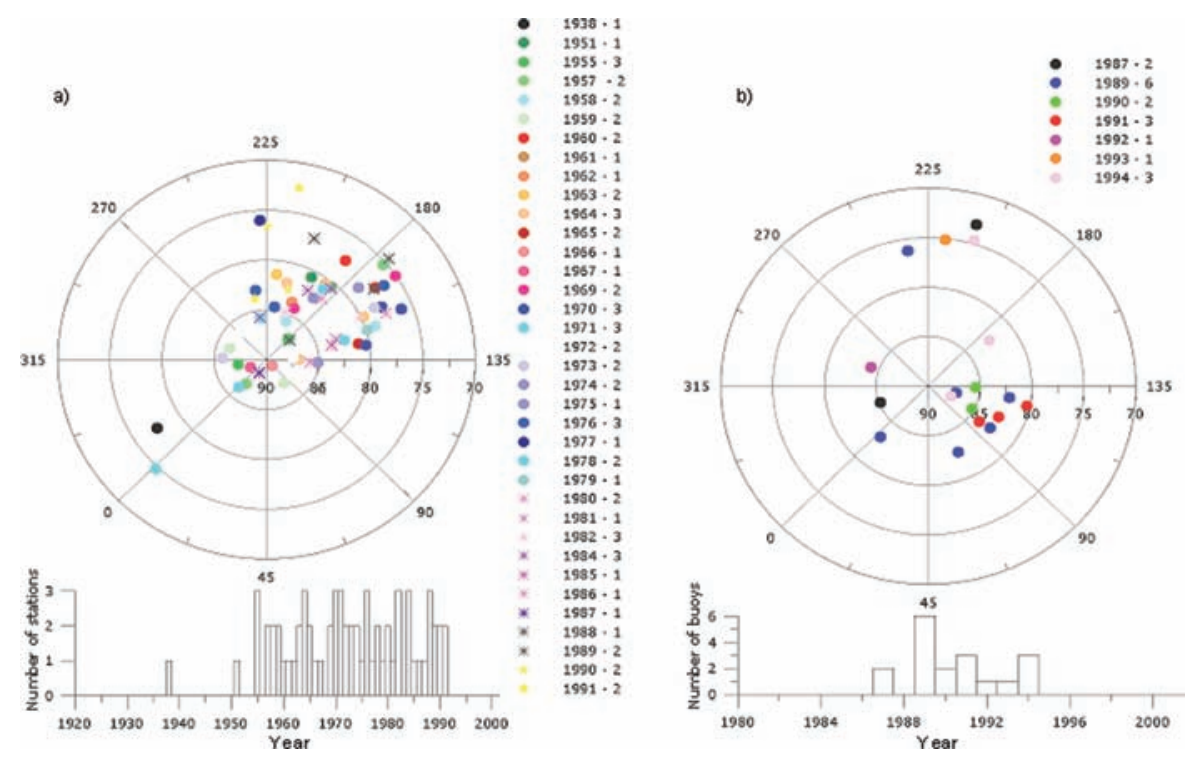

Fig. 7. Spatial location and temporal distribution of number of Russian drifting stations (a) and ARGOS buoys (b) for January. 
almost the same station database as N. CRUTEM $2 \mathrm{v}$ - essentially akin to data set $\mathbf{J}$-is a variance-corrected gridded version of CRU data set which is produced directly from monthly station data (Jones and Moberg, 2003) using the CAM. The CAM technique requires that each station be reduced to the anomalies from monthly means calculated for a common period (Jones et al., 1999). Variance correction adjusts each grid box series in a way that the time series values are not influenced by the temporally varying number of contributing stations (see Jones et al., 2001; Jones and Moberg, 2003).

In order to perform a comparison, we derived gridded monthly mean time series of SAT from data set $\mathbf{N}$. Using these time series, qualitative and quantitative estimates of the temperature distribution and trends for the given region and their comparison with CRUTEM2v and ERA-40 data sets were obtained. The accuracy of the analyses and measure of the interpolation errors in each grid point were estimated as well.

\subsection{Spatially averaged time series}

We considered temperature anomalies relative to 1961-1990 from data sets CRUTEM2v and the data set N. Figure 8 shows the time evolution of the 11-yr running mean SAT anomalies for four midseason months-January, April, July and October, and annual anomalies for different latitudinal zones: $40-60^{\circ} \mathrm{N}$ and $60-90^{\circ} \mathrm{N}$. Averaging was made with the area weighting by cosine of the central latitude of each grid box. Figure 8 again indicates two periods of high-latitude warming: 1920-1940, and since the mid-1970s, as was evident to varying degree in data sets $\mathbf{A}, \mathbf{J}, \mathbf{H}$ and $\mathbf{E}$ (Figs. 2-4). Figure 8 also shows that for the region $40-60^{\circ} \mathrm{N}$ the CRUTEM $2 \mathrm{v}$ and $\mathbf{N}$ data sets practically coincide. The larger differences between them occur generally during the early-20th-century warming for the polar region 60 $90^{\circ} \mathrm{N}$. There is also a significant difference in 1900-1999 trends (see Table 4), especially for the polar region in spring (April).
Fig. 8. 11-yr running mean SAT anomalies in January, July, April, October and annual SAT anomalies for different latitudinal zones: $60-90^{\circ} \mathrm{N}$ and $40-60^{\circ} \mathrm{N}$. Black-CRUTEM2v, grey-NansenSAT data set.
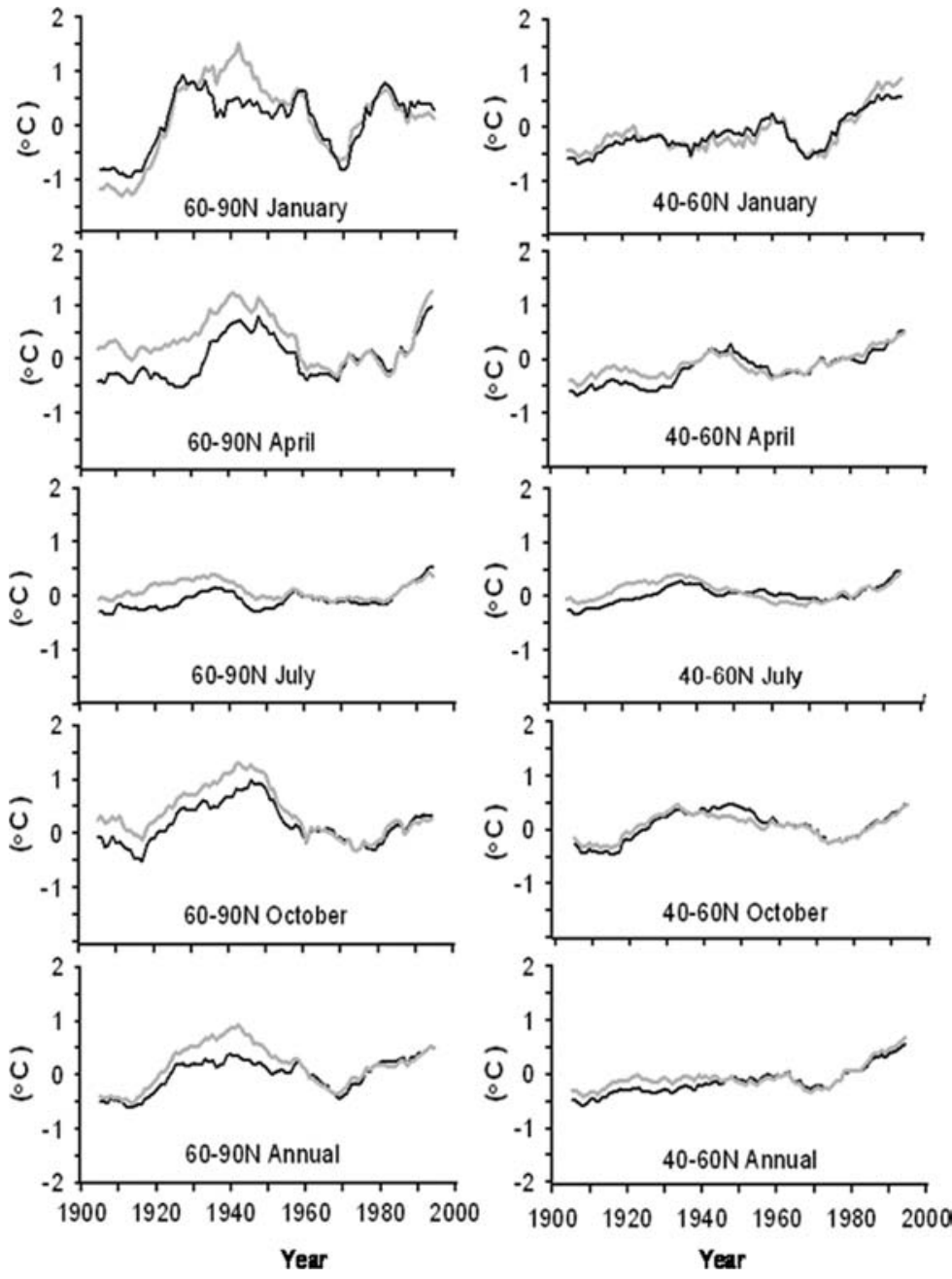
Table 4. Linear temperature trends over the region $60-90^{\circ} \mathrm{N}$ for April $\left({ }^{\circ} \mathrm{C} / 100 \mathrm{yr}\right)$ for the NansenSAT and CRUTEM2v data sets. Trends significant at $\alpha<0.05$ are highlighted in bold.

\begin{tabular}{lc}
\hline Data set & Trend \\
\hline CRUTEM2v & $\mathbf{0 . 8 9}$ \\
NansenSAT & 0.15 \\
NansenSAT, without boxes where & \\
$\quad$ there are gaps in CRUTEM2v data & $\mathbf{0 . 6 5}$ \\
CRUTEM2v, Land only & $\mathbf{0 . 8 5}$ \\
NansenSAT, Land only & $\mathbf{0 . 6 6}$ \\
\hline
\end{tabular}
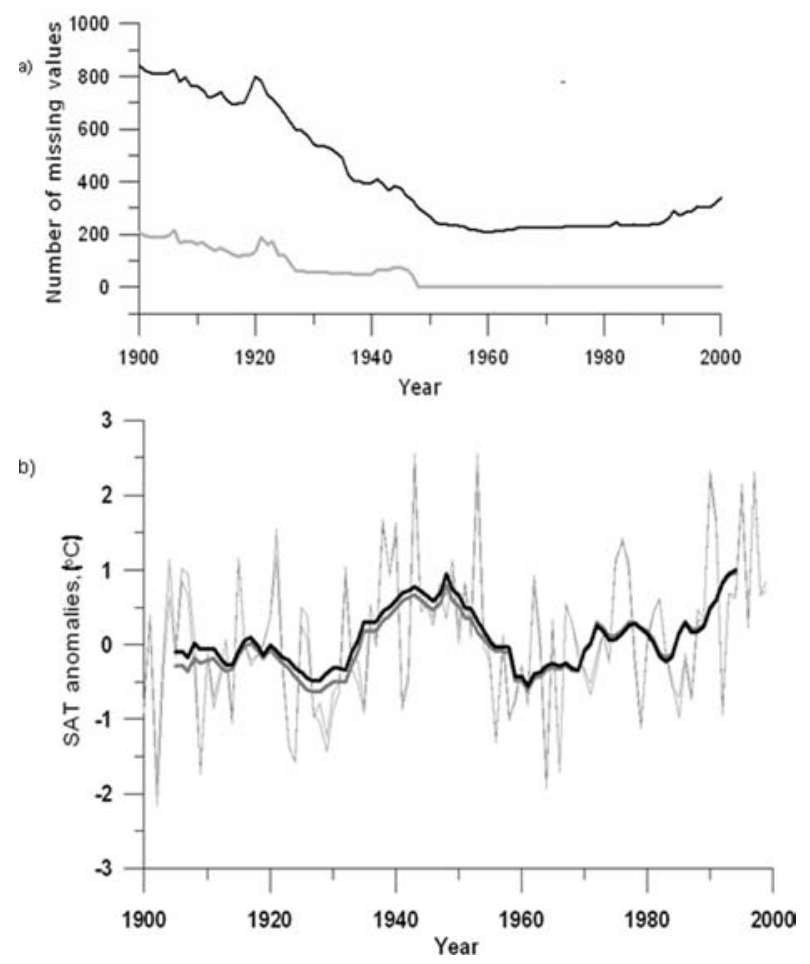

Fig. 9. (a) Number of missing values over the land only in the NansenSAT (grey) and CRUTEM2v (black) data sets. (b) Averaged temperature anomalies over the area $60-90^{\circ} \mathrm{N}$ for April for NansenSAT (grey) and CRUTEM2v (black) data sets calculated using the same number of grid sells for both data sets for the land only. Thick lines-10 yr running means; thin lines—unsmoothed time series.

These differences can be explained by the different spatial coverage in the two data sets, coverage defined by the gridding techniques applied. For example, Fig. 9a shows that the number of missing values (on an annual basis) over land for CRUTEM2v is four times larger than for data set $\mathbf{N}$ and the 'implicit assumption is made that the average temperature in the unavailable areas is equal to that in the areas covered by data sampling' (Jones and Moberg, 2003). Therefore, larger differences between the data sets occur in the regions where data set $\mathbf{N}$ and CRUTEM2 $v$ employ essentially different quantities of the data for averag- ing. We calculated averaged temperature anomalies over the area $60-90^{\circ} \mathrm{N}$ for April (namely the region and month where largest difference in trends was found), using the same number of grid cells for the CRUTEM2v and $\mathbf{N}$ data sets for the land only. The result of this calculation is presented in the Fig. $9 \mathrm{~b}$. In contrast to Fig. 8, averaged SAT anomalies for the CRUTEM2 $\mathrm{v}$ and $\mathbf{N}$ data sets here are rather close. Then we calculated the averaged temperature anomalies for the same area and month, but excluding from the $\mathbf{N}$ data set those grid boxes where CRUTEM2v indicates gaps (in this case the numbers of grid boxes used over the ocean are slightly different). The values of linear trends obtained for these various cases are presented in Table 4. The use of the same number of grid boxes for CRUTEM2 $v$ and $\mathbf{N}$ data sets significantly reduces the difference between the trends. The remainder of the difference between the trends can be explained by the respective gridding techniques. Whereas the CAM method employed for CRUTEM2v uses data only inside grid meshes, $\mathbf{N}$ uses data also from nearby stations located outside the meshes owing to the OI technique.

This example illustrates the problem of using trends and considering the trend significance for the limited regions. It should be also noted that, as recently was shown by Bengtsson et al. (2006), 50-yr trends with 95\% significance are caused not necessarily by external changes, but may also evolve by chance as a result of internal fluctuations of the climate system.

Much closer agreement between the $\mathbf{N}$ and CRUTEM2v data sets was found for the period of ECMWF Reanalysis (ERA-40), 1958-1999. Table 5 shows correlations between temperature anomalies of ERA-40 (E), NansenSAT (N) and CRUTEM2v for two latitudinal zones. For the polar region (60$90^{\circ} \mathrm{N}$ ) the correlation is higher between ERA-40 and NansenSAT, as both basically use the OI method. For the region 40$60^{\circ} \mathrm{N}$, the ERA-40/CRUTEM2v correlation is generally higher.

\subsection{Zonal averages and spatial trends}

Figure 10 shows the time evolution of the zonally averaged SAT anomalies over $40-90^{\circ} \mathrm{N}$ for four midseason months (January, July, April and October). These results from data set $\mathbf{N}$ agree with data from $\mathbf{J}$ and $\mathbf{A}$, with less agreement with the $\mathbf{H}$ data (see Figs. 2-4).

Table 5. Correlation between ERA-40, NansenSAT and CRUTEM2v time series over 1958-1999 for different months and latitude bands.

\begin{tabular}{lcclcc}
\hline Month & \multicolumn{2}{c}{ ERA/NansenSAT } & & \multicolumn{2}{c}{ ERA/CRUTEM2v } \\
\cline { 2 - 3 } \cline { 6 - 6 } & $60-90^{\circ} \mathrm{N}$ & $40-60^{\circ} \mathrm{N}$ & & $60-90^{\circ} \mathrm{N}$ & $40-60^{\circ} \mathrm{N}$ \\
\hline January & 0.97 & 0.98 & & 0.81 & 0.98 \\
July & 0.96 & 0.89 & & 0.90 & 0.94 \\
April & 0.96 & 0.95 & & 0.88 & 0.95 \\
October & 0.95 & 0.97 & & 0.84 & 0.98 \\
\hline
\end{tabular}



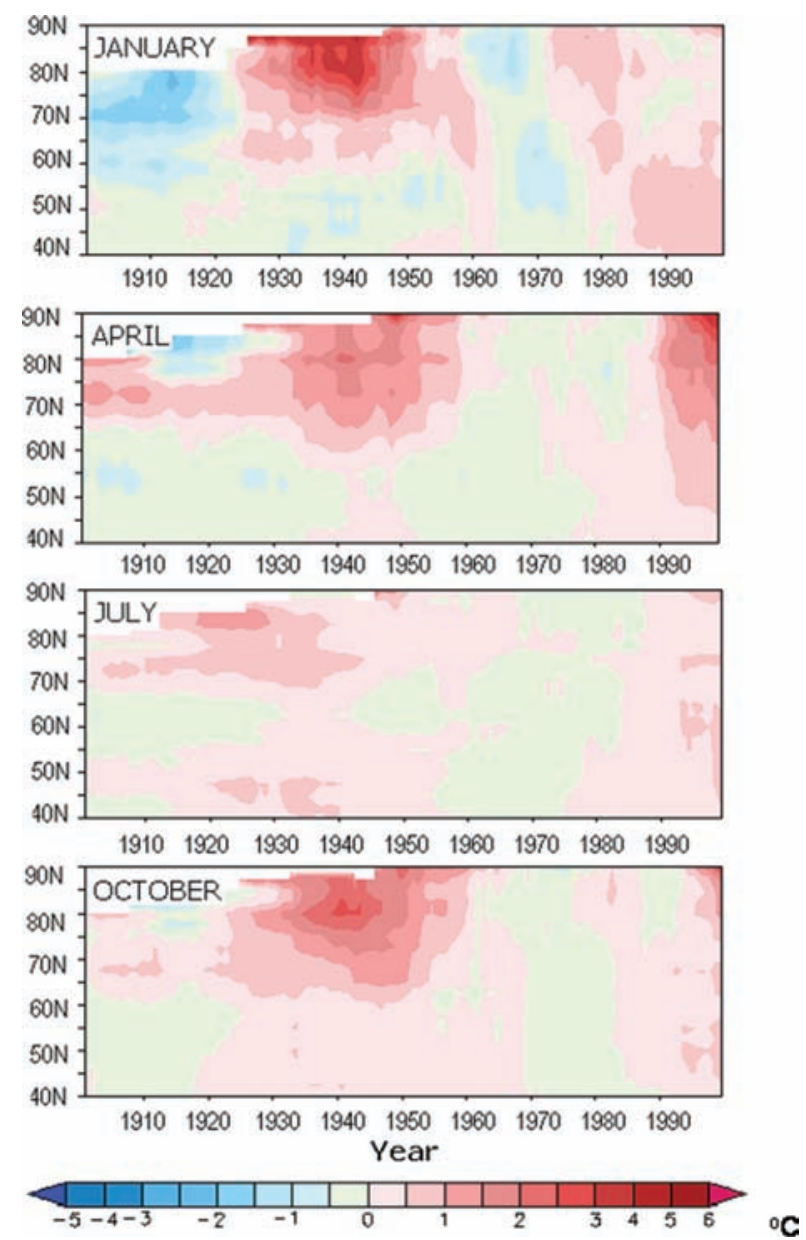

Fig. 10. Hovmöller diagram indicating the time-latitude variability of NansenSAT anomalies north of $40^{\circ} \mathrm{N}$ in January, April, July and October.

We also consider the spatial distribution of linear temperature trends for the periods of warming and cooling. Figure 11 shows data set $\mathbf{N}$ trends to the north of $40^{\circ} \mathrm{N}$ in January and July for 20-yr periods representing warming and cooling in the twentieth century: 1920-1939, 1945-1964 and 1980-1999. Comparison shows that the data set $\mathbf{N}$ trend patterns are similar to those from the $\mathbf{A}$ data set. The major difference between these two data sets and Reanalysis data is statistically significant warming trend in the central Arctic in the $\mathbf{N}$ and $\mathbf{A}$ data sets in January, comparing to slight cooling in ERA-40 data. It is difficult to judge the correctness of these estimates because there has been controversy regarding recent Arctic temperature trends (see Table 6). Since the trends in the recent decades over the central Arctic Ocean vary, according to different studies, from significant warming (Rigor et al., 2000) to strong cooling (Kahl et al., 1993), though the latter estimate was based on the data only from 1950 to 1990 , before more recent measurements have shown dramatic warming in the central Arctic.

\subsection{Estimation of the analysis accuracy}

Figure 12 shows the envelope containing mean square of the relative interpolation error for each month. The errors are higher for the early-20th-century. Errors are minimal during 1950-1990 because of good station density in that period, and increase again over the last decades. Figure 13 presents the spatial distribution of the mean square relative error of interpolation $\varepsilon$ and the mean square absolute interpolation error $E$ for three periods: 19001930, 1930-1960 and 1960-1990. Vast areas exist where the current information on the temperature field is very scarce, especially as relates to the areas where $\varepsilon>0.4$ (Central Arctic, some ocean areas). However, the absolute interpolation error is not very high in the above regions because of low variability in temperature values.

As a next step, we estimated the magnitude of errors caused by using the data from insufficient number of stations. In order to calculate actual error we mimicked previous data sets by reducing the data set for the period 1980-2000 to the observational network of previous periods. We calculated mean temperature fields for the period 1980-2000 for January and July using station density of the beginning of the century. Figure 14 shows the difference between mean (1980-2000) temperature fields, calculated using: (1) actual 1980-2000 station network and (2) data reduced to the observational network of 1900-1920 period. The errors lie mainly within the interval $\pm 2{ }^{\circ} \mathrm{C}$. In January, the maximum error (up to $8{ }^{\circ} \mathrm{C}$ ) occurred over Siberia. In July, the difference between these two calculations is smaller and do not exceed $4{ }^{\circ} \mathrm{C}$. This result illustrates the idea that percentage coverage is more important for the quality of calculations than the number of stations.

\section{Summary and conclusions}

We have compared several gridded SAT data sets for the region north of $40^{\circ} \mathrm{N}$. The data sets considered are obtained by different methods of interpolation of the meteorological station data to a regular grid. Each of these gridding techniques represents a valid approach, although each has its own advantages and limitations. All interpolation methods yield results that nearly coincide and are sufficiently accurate within regions with a dense network. In the case of oversampling in some regions (e.g. North America), schemes that have a large grid-cell size, like the Reference Station Method, produce significantly better estimates than schemes using small grid cells (Karl et al., 1993). However, for a sparse network, the success of each method decreases differently. In cases where information is scarce-such as large areas in the high latitudes - the most effective for spatial averaging of meteorological fields are statistically optimal methods (Gandin, 1965).

The cross-correlations between all four data sets over the land areas are $0.8<r<0.9$, and are highest in the North 


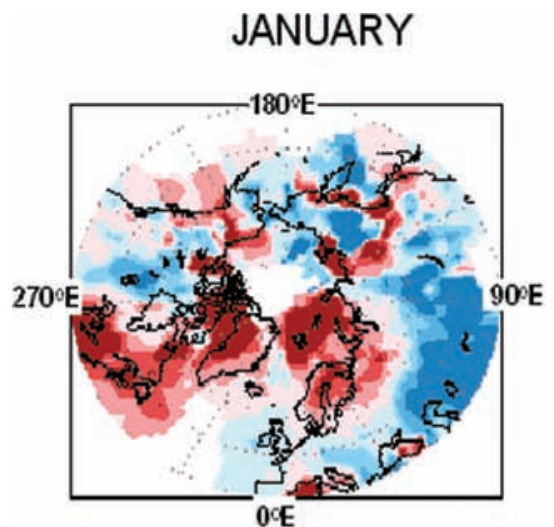

a)
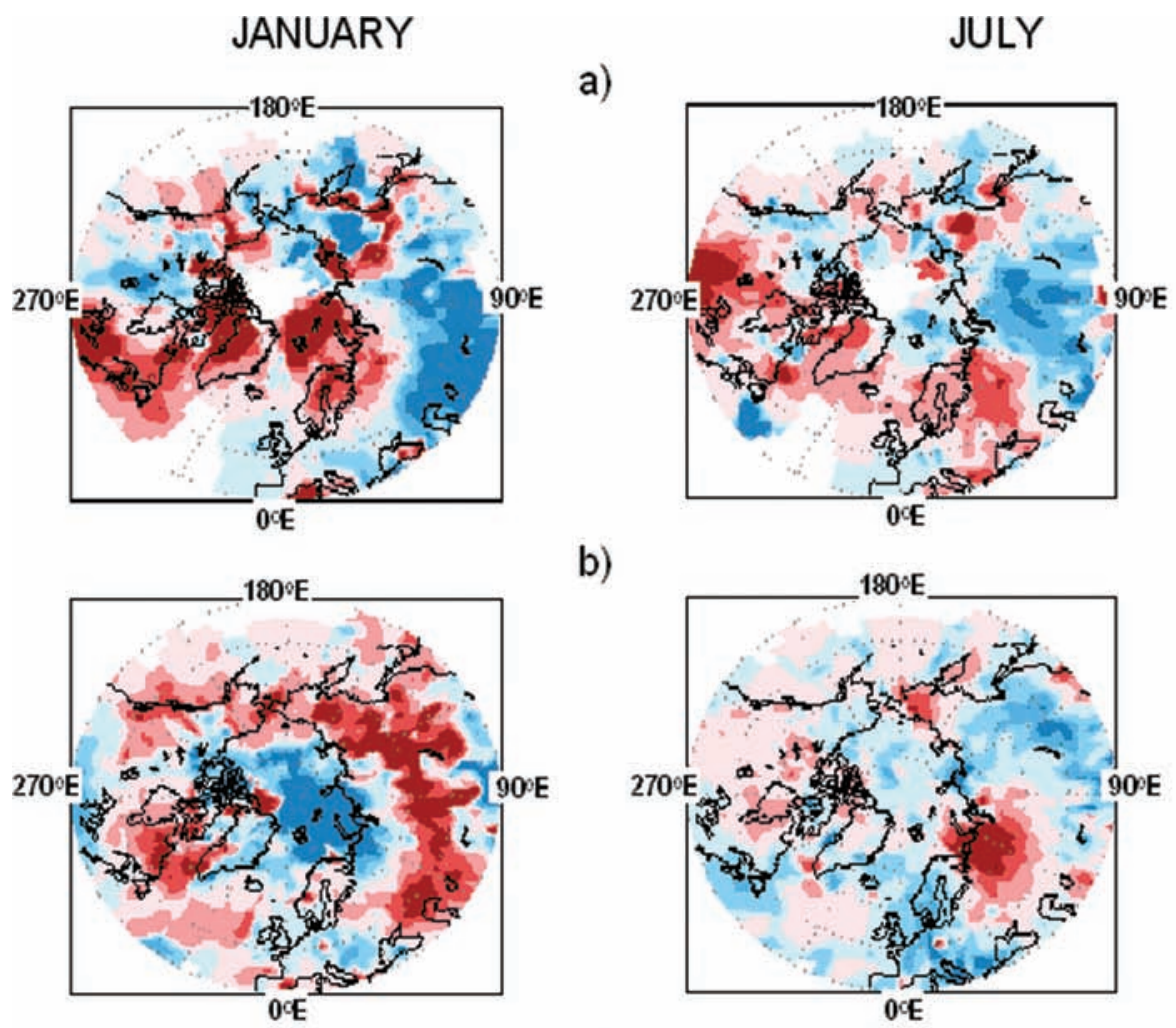

b)

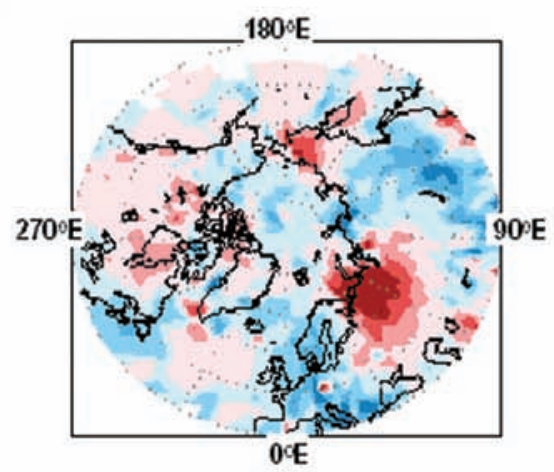

$180^{\circ} \mathrm{E}$

c)

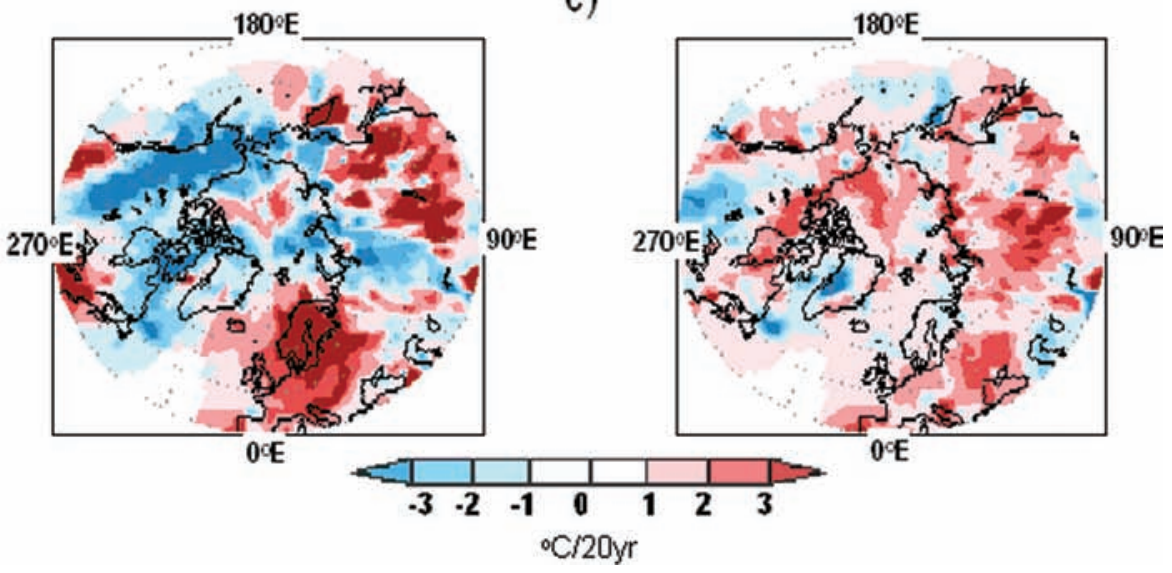

Fig. 11. Observed NansenSAT trends in SAT north of $40^{\circ} \mathrm{N}$ in January and July for 20-yr periods representing warming, cooling and warming in the 20th century, respectively: (a) 1920-1939; (b) 1945-1964, (c) 1980-1999.

American and western European regions, where the station density is higher. For the ocean areas, the correlations are substantially lower $(0.2<r<0.4)$. Analysis of time evolution of averaged temperature anomalies for different latitudinal zones indicated that the greater differences between data sets occur during the $1920 \mathrm{~s}-1930 \mathrm{~s}$ warming period for the area $60-90^{\circ} \mathrm{N}$. Differences in 1900-1999 linear trends reach $0.64{ }^{\circ} \mathrm{C} / 100 \mathrm{yr}$, particularly in October and July for the polar region $\left(60-90^{\circ} \mathrm{N}\right)$.

Comparison of the spatial distribution of linear temperature trends for the periods of warming and cooling reveals similarities as well as regional differences for all the data sets. The warming in both the 1920-1939 and 1980-1999 periods was most pronounced in January for the Arctic region. This is evident from all data sets, though only data sets $\mathbf{A}$ and $\mathbf{E}$ have no gaps in the central Arctic. The major difference here is statistically significant warming trend in the central Arctic in January in data set A, comparing to slight cooling in data set $\mathbf{E}$. This is the subject for discussion and further analysis, as there has been some controversy regarding arctic temperature trends (e.g. Jones et al., 1999). 
Table 6. Arctic temperature trends ${ }^{\mathrm{a}}\left({ }^{\circ} \mathrm{C}\right.$ per decade) estimated from various data sets for various time intervals and regions.

\begin{tabular}{|c|c|c|c|c|c|}
\hline \multirow[b]{2}{*}{ Author } & \multirow[b]{2}{*}{ Data sources, time interval and region } & \multicolumn{4}{|c|}{ Season } \\
\hline & & Winter & Spring & Summer & Autumn \\
\hline Chapman and Walsh (1993) & Land station temperatures, 1961-1990 & +0.25 & +0.5 & $\sim 0$ & $\sim 0$ \\
\hline Kahl et al. (1993) & $\begin{array}{l}\text { Western Arctic, 1950-1990 } \\
\text { (U.S. dropsonde data, 1950-1961; radiosonde } \\
\text { data from North Pole drifting stations, 1954- } \\
\text { 1990) }\end{array}$ & -1.1 & & & -1.2 \\
\hline Martin et al. (1997) & $\begin{array}{l}\text { Central Arctic ocean, 1961-1990 } \\
\text { (buoy, North Pole, and coastal station temper- } \\
\text { atures) }\end{array}$ & +0.35 & +0.2 & +0.2 & -0.2 \\
\hline Alexandrov et al. (2004) & $\begin{array}{l}\text { Russian North Pole drifting stations, 1955- } \\
1990 \\
\text { Mean coordinate for all drifting stations } \\
82.4^{\circ} \mathrm{N}, 175.0^{\circ} \mathrm{W}\end{array}$ & +0.27 & -0.15 & +0.08 & -0.2 \\
\hline \multirow[t]{5}{*}{ Rigor et al. (2000) } & $\begin{array}{l}\text { Buoys, manned drifting stations, and meteo- } \\
\text { rological land stations in the Arctic, 1979- } \\
1997\end{array}$ & & & & \\
\hline & $\begin{array}{l}\text { Eastern Greenland, Europe, Eurasia, extend- } \\
\text { ing north of Laptev Sea }\end{array}$ & +2.0 & +2.0 & No significant trend & \\
\hline & $\begin{array}{l}\text { Beaufort Sea and Eastern Siberia, extending } \\
\text { into Alaska }\end{array}$ & -2.0 & over most of the Arctic & & \\
\hline & $\begin{array}{l}\text { Over coast of Greenland, near Iceland, in } \\
\text { Siberia }\end{array}$ & & & & +2.0 \\
\hline & Beaufort Sea, Alaska & & & & -1 \\
\hline
\end{tabular}

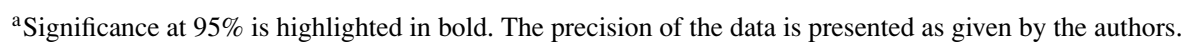

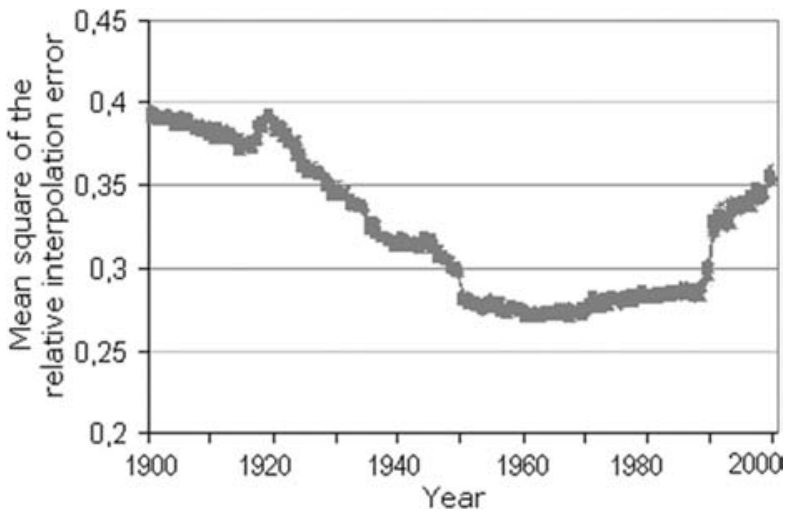

Fig. 12. Envelope containing the mean square of the relative interpolation error for the NansenSAT data for each month.

Incomplete spatial sampling can introduce significant errors into the linear trends of the temperature, especially during the early 20th century. The discrepancies found suggest caution in estimating linear trends and their significance for limited regions in the high latitudes. These findings clearly indicate the strong need for further improvements of data sets both spatially and temporally.
Here, the new NansenSAT $2.5^{\circ} \times 2.5^{\circ}$ gridded data set has been created for the region north of $40^{\circ} \mathrm{N}$ for the period 1900 2000, using all available SAT data including land meteorological stations, ARGOS buoys, Russian and western drifting stations, and Russian patrol ships, optimally interpolated using the OA method.

The new SAT data set was shown to agree broadly with existing data sets within their common coverage. However, the main advantage of the new data set is its enhanced spatial coverage. This was achieved by: (1) The involvement of additional data used in the NansenSAT data set, which were not employed by the previous data sets and (2) the implementation of the enhanced OA technique that allows for the optimal use of the data outside the current grid cell, if the information is scarce.

The differences found between NansenSAT and CRUTEM2v data sets arise from: (1) additional data used in the NansenSAT data set (ARGOS buoys, Russian drifting station data, etc.); (2) different sources of data over the ocean regions (CRUTEM2v used SST from Hadley centre, whereas NansenSAT does not) and (3) a significant decrease of the number of missing values over the land for NansenSAT data set at the beginning of the 20th century as compared to CRUTEM2v data set, and due to the use of the enhanced OA. Our analysis depends on ERA-40 data, which is used a climatic norm. However, its influence is 

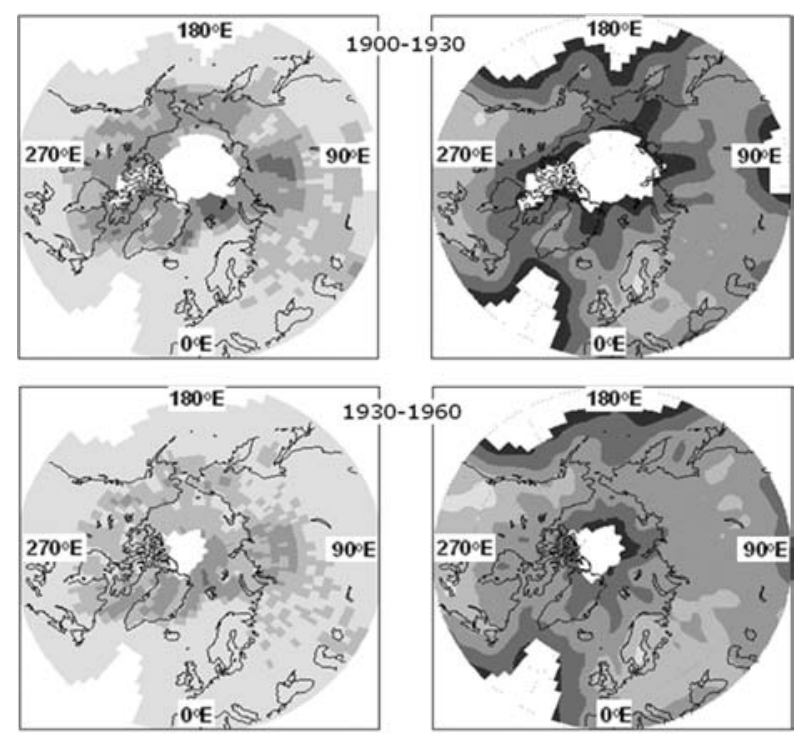

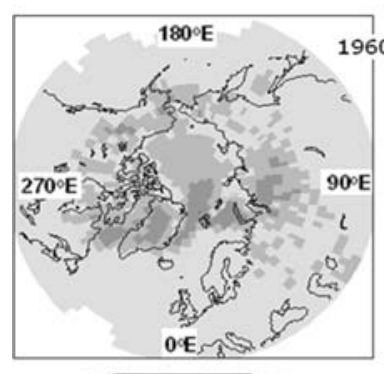

$\begin{array}{llll}2 & 4 & 8 & 12\end{array}{ }^{\circ} \mathrm{C}$

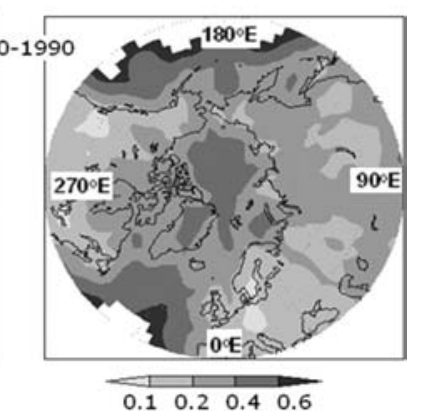

$\begin{array}{llll}0.1 & 0.2 & 0.4 & 0.6\end{array}$
Fig. 13. Spatial distribution of the mean square of the relative (right) and absolute (left) interpolation errors for the NansenSAT data for three time periods: 1900-1930, 1930-1960 and 1960-1990.

only essential for the regions with a sparse network. In turn, ERA-40 is not independent of the CRUTEM2v data as a lot of meteorological station data are used in the ERA-40 analysis.

The new data set NANSENSAT has been validated by its comparison with the other existing data sets in the regions with their common coverage. It has been shown to have distinct advantage in the regions, where information is scarce. This, together with its availability through the Web, makes this new data set useful for the investigation of the climate of high and middle latitudes.

The new NansenSAT data set described in this paper and its updates are available via the website of the Nansen International Environmental and Remote Sensing Center (NIERSC), St. Peterburg, Russia (http://www.niersc.spb.ru/NANSEN_SAT_ gridded.rar).

\section{Acknowledgments}

This work has been supported by the Research Council of Norway through the MACESIZ, ROLARC and ARCWARM projects and from a grant from the Norwegian Ministry of Edu-

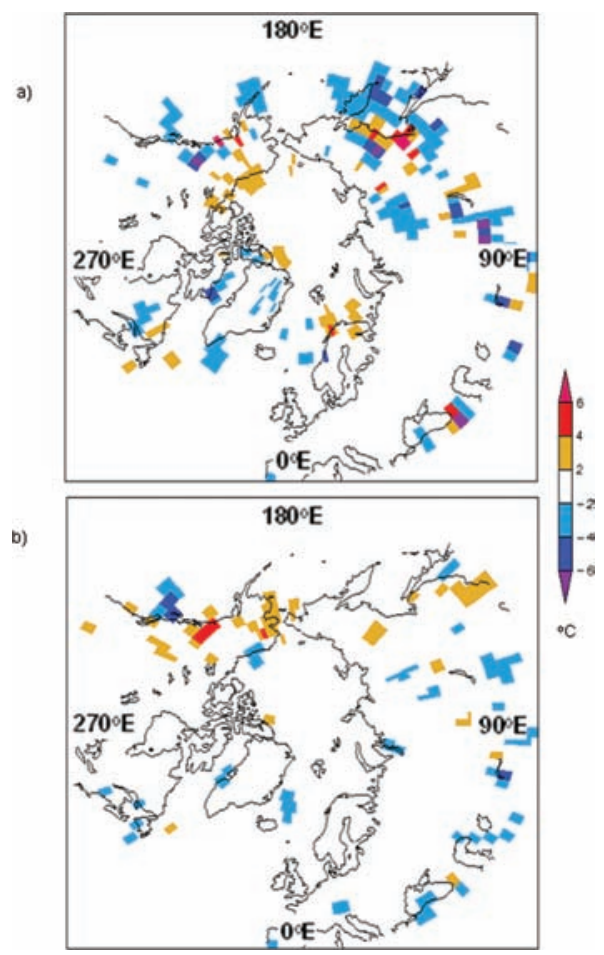

Fig. 14. Difference between mean (1980-2000) temperature fields calculated using the actual 1980-2000 station network and using the data reduced to the observational network of the 1900-1920 period for January (a) and July (b).

cation and Research to the Nansen International Environmental and Remote Sensing Center in St. Petersburg, managed by the Research Council of Norway. Furthermore two of the authors (SIK and LPB) was funded by the EU Descartes Prize through the project 'Climate and Environmental Changes in the Arctic - CECA' headed by Ola M. Johannessen. This paper is also a contribution to the IPY-Climate of the Arctic and its role for Europe (IPY-CARE) with Ola M. Johannessen as the Principal Investigator.

The authors would like to thank Prof. Phil D. Jones for providing the station temperature data set and Martin W. Miles for consultation on formulating and presenting the results.

\section{APPENDIX A: Objective Analysis Method}

According to the OA method, the temperature anomaly $\Delta T$ (the deviation of observed value from climatic 'norms') at a given grid-point $k$ can be expressed as a linear combination of temperature anomalies at the points of observations $\Delta T_{i}$ (Gandin, 1965):

$\Delta \mathrm{T}_{k}=\sum_{i=1}^{n} W_{k i} \Delta T_{i}$,

where $W_{k i}$ isthe interpolation weights, $n$ is the number of observational stations used. 
For every grid-point interpolation, weights $W_{k i}$ are obtained by solving a matrix equation:

$(C+O) W_{k}=c_{\mathrm{k}}$,

where $\boldsymbol{c}_{\boldsymbol{k}}$ describes the correlation between background temperature values at a grid-point $k$ and observational points, matrix $\boldsymbol{C}$ represents correlation of climatic 'norms' at observational points, and $\boldsymbol{O}$ is a matrix of the mean square relative errors of observations.

There are two main stages in creating the temperature data set:

1. Preliminary operations: calculation of the SAT monthly climatic norms and autocorrelation functions

2. OI, including:

(i) Searching the influencing stations by means of successive extraction of information from nearby regions in order to facilitate the uniform location of the influencing stations relative to the grid point. It is not desirable to take a large number of influencing stations. Therefore the extraction stops at $n=8$. If there are no influencing stations within the area with "radius of influence" $R^{*}=200 \mathrm{~km}$, then influencing stations are searched in the broader region adding $50 \mathrm{~km}$ to $R^{*}$ and repeating it, if necessary, until the maximum area radius becomes $900 \mathrm{~km}$

(ii) Determining the interpolation weights $\boldsymbol{W}_{\boldsymbol{k}}$ by solving equation (2) using Gauss method with pivotal elements

(iii) Interpolation itself, including:

(a) determination of the temperature anomalies at the influencing stations by subtracting the norms from the observed values;

(b) calculation of the anomaly at the grid point using (1);

(c) addition of the climatic norm at the grid point to the calculated anomaly;

(d) calculation of the interpolation errors. The mean square relative error of the interpolation $\epsilon_{k}$ is expressed by the following equation:

$\varepsilon_{k}=\frac{E_{k}}{d_{k}^{2}}=1-\sum_{i=1}^{n} W_{k i} c_{k i}, 0 \leq \varepsilon_{k} \leq 1$,

where $E_{k}$ is the absolute interpolation error and $d_{k}^{2}$ is the variance.

In this manner, we obtain a value of SAT for every point of a grid in succession.

\section{References}

Arctic Climate Impact Assessment (ACIA). 2005. Scientific Report. Cambridge University Press, Cambridge, 1042 pp.

Arctic Climatology Project. 2000. Environmental Working Group Arctic Meteorology and Climate Atlas (eds F. Fetterer and V. Radionov). National Snow and Ice Data Center, Boulder, CO, CD-ROM.

Alexandrov, E., Bryazgin, N., Dement'ev, A. and Radionov, V. 2004. Meteorological Regime of the Arctic Basin (from Drifting Station Data). Volume 2 (ed. G. Alekseev). Gidrometeoizdat, St. Petersburg, 144 pp.
Alekseev, G. V. and Svyaschennikov, P. N. 1991. Natural Variability of Climate Characteristics in Northern Polar Region and Northern Hemisphere. Gidrometeoizdat, St. Petersburg, Russia, 159 pp. (in Russian).

Alekseev, G. V., Aleksandrov, Ye. I., Bekriayev, R. V., Svyashchennikov, P. N., Harlanienkova, N. Ye. and co-authors. 1999. Surface air temperature from meteorological data. In: Detection and Modelling of Greenhouse Warming in Arctic and sub-Arctic, INTAS Grant 97-1277 Technical Report on Task 1, Arctic and Antarctic Research Institute, St. Petersburg, Russia.

Bengtsson, L., Hodges, K., Roeckner, E. and Brokopf, R. 2006. On the natural variability of the pre-industrial European climate. Clim. Dyn. 27, 743-760.

Bengtsson, L., Semenov, V. A. and Johannessen, O. M. 2004. The early twentieth-century warming in the Arctic-a possible mechanism. $J$. Climate 17, 4045-4057

Chapman, W. L., and J. E. Walsh. 1993. Recent variations of sea ice and air temperature in high latitudes. Bull. Am. Meteorol. Soc. 74, 33-47.

Douville, H., Mahfouf, J.-F., Saarinen, S. and Viterbo, P. 1998. 'The ECMWF surface analysis: diagnostics and prospects'. ECMWF Tech. Memo. No. 258. European Centre for Medium-Range Weather Forecasts, Shinfield, Reading, UK.

Frolov, I. E., Gudkovich, Z. M., Radionov, V. F., Shirochkov, A. V., Timokhov, L. A. 2005. The Arctic Basin-Results from the Russian Drifting Stations. Springer, Berlin, 273 pp.

Gandin, L. S. 1965. Objective Analysis of Meteorological Fields. Gidrimeteoizdat, Leningrad. Translated by Israel Program of Scientific Translations, Jerusalem, 242 pp.

Hansen, J. E. and Lebedeff, S. 1987. Global trends of measured surface air temperature. J. Geophys. Res. 92, 13345-13372.

Hansen, J., Ruedy, R., Glascoe, J. and Sato, M. 1999. GISS analysis of surface temperature change. J. Geophys. Res. 104, 30997-31022.

Hansen, J., Sato, M., Ruedy, R., Lo, K., Lea, D. W. and Medina-Elizade, M. 2006. Global temperature change. Proc. Natl. Acad. Sci. 103, 14288-14293.

Intergovernmental Panel on Climate Change (IPCC). 2007. The physical science basis. Working Group I Contribution to the Fourth Assessment Report of the IPCC. Cambridge University Press, Cambridge, UK.

Johannessen, O. M., Bengtsson, L., Miles, M. W., Kuzmina, S. I., Semenov, V. A., and co-authors. 2004. Arctic climate change: ob-

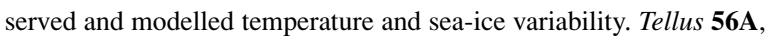
328-341.

Jones, P. D., New, M., Parker, D. E., Martin, S. and Rigor, I. G. 1999. Surface air temperature and its variations over the last 150 years. Rev. Geophys. 37, 173-199.

Jones, P. D., Osborn, T. J., Briffa, K. R., Folland, C. K., Horton, B. and co-authors. 2001. Adjusting for sampling density in grid-box land and ocean surface temperature time series. J. Geophys. Res. 106, 33713380 .

Jones, P. D. and Moberg, A. 2003. Hemispheric and large-scale surface air temperature variations: an extensive revision and an update to 2001. J. Climate 16, 206-223.

Kagan, R. L. 1997. Averaging of Meteorological Fields. 379 pp. Kluwer Acad., Norwell, Mass.

Kahl, J. D., Charlevoix, D. J., Zaitseva, N. A., Schnell, R. C. and Serreze, M. C. 1993. Absence of evidence for greenhouse warming over the Arctic Ocean in the past 40 years. Nature 361, 335-337. 
Karl, T. R., Knight, R. W. and Christy, J. R. 1993. Global and hemispheric temperature trends: Uncertainties related to inadequate spatial sampling. J. Climate 7, 1144-1163.

Martin, S., Munoz, E. A. and Drucker, R. 1997. Recent observations of a spring-summer surface warming over the Arctic Ocean. Geophys. Res. Lett. 24, 1259-1262.

Overland, J. E, Spillane, M. C., Percival, D. B., Wang, M. and Mofjeld, H. O. 2004. Seasonal and regional variation of pan-Arctic surface air temperature over the instrumental record, 1871-2000. J. Geophys. Res. 108, 4407-4410.

Peterson, T. C., Karl, T. R., Jamason, P. F., Knight, R. and Easterling, D. R. 1998. The first difference method: Maximizing station density for the calculation of long-term global temperature change. J. Geophys. Res. 103, 25967-25974.

Polyakov, I. V. and Johnson, M. A. 2000. Arctic decadal and interdecadal variability. Geophys. Res. Lett. 27, 4097-4100.

Polyakov, I. V., Johnson, M. A., Colony, R. L., Bhatt, U. and Alekseev, G. V. 2002. Observationally based assessment of polar amplification of global warming. Geophys. Res. Lett. 29, 1878, doi:1029/2002GL011111.

Polyakov, I., Bekryaev, R. V., Alekseev, G. V., Bhatt, U. S., Colony, R. L. and co-authors. 2003. Variability and trends of air temperature and pressure in the maritime Arctic, 1875-2000. J. Climate 16, 20672077.

Przybylak, R. 2000. Temporal and spatial variation of surface air temperature over the period of instrumental observations in the Arctic. Int. J. Climatol. 20, 587-614.

Rayner, N. A., Parker, D. E., Horton, E. B., Folland, C. K., Alexander, L. V. and co-authors. 2003. Globally complete analyses of sea surface temperature, sea ice and night marine air temperature, 1871-2000. J. Geophys. Res. 108, 4407, doi:10.1029/2002JD002670.
Reynolds, R. W., Rayner, N. A., Smith, T. M., Stokes, D. C. and Wang, W. 2002. An improved in situ and satellite SST analysis for climate. J. Climate 15, 1609-1625.

Reynolds, R. W. and Smith, T. M. 1994. Improved global sea surface temperature analyses using optimal interpolation. J. Climate 7, 929948.

Rigor, I. G., Colony, R. L. and Martin, S. 2000. Variations in surface air temperature observations in the Arctic, 1979-1997. J. Climate 13, 896-914.

Schlesinger, M. E. and Ramankutty, N. 1994. An oscillation in the global climate system of period $65-70$ years. Nature 367, 723726.

Serreze, M. C., Walsh, J. E., Chapin, F. S., Osterkamp, T., Dyurgerov, M. and co-authors. 2000. Observational evidence of recent changes in the northern high-latitude environment. Clim. Change 46, 159207.

Simmons, A. J., Jones, P. D., da Costa Bechtold, V., Beljaars, A. C. M., Kållberg, P. W. and co-authors. 2004. Comparison of trends and lowfrequency variability in CRU, ERA-40, and NCEP/NCAR analyses of surface air temperature. J. Geophys. Res. 109, D24115.

Smith, T. M., Reynolds, R. W., Livezey, R. E. and Stokes, D.C. 1996. Reconstruction of historical sea surface temperature using empirical orthogonal functions. J. Climate 9, 1403-1420.

Uppala, S. M., Kållberg, P. W., Simmons, A. J., Andrae, U., da Costa Bechtold, V. and co-authors. 2005. The ERA-40 re-analysis. Quart. J. Royal Meteorol. Soc. 131, 2961-3012.

Vinnikov, K. Ya. 1977. On the issue of data production and interpretation of NHSAT change for 1881-1975. Met. Gidr. 9, 110-114 (in Russian).

Zhang, R., Delworth, T L. and Held, I. M. 2007. Can the Atlantic Ocean drive the observed multidecadal variability in Northern Hemisphere mean temperature? Geophys. Res. Lett. 34, 2, L02709. 